\title{
Development of low-volume, high-intensity, aerobic-type interval training for elderly Japanese men: a feasibility study
}

Yosuke Osuka ${ }^{1,2^{*}}$, Muneaki Matsubara ${ }^{3}$, Ai Hamasaki $^{4}$, Yuji Hiramatsu ${ }^{3}$, Hiroshi Ohshima ${ }^{2}$ and Kiyoji Tanaka ${ }^{5}$

\begin{abstract}
Background: The purposes of this study were to identify 1 ) the feasibility of a novel exercise protocol (elderly Japanese male version of high-intensity interval aerobic training: EJ-HIAT) and 2) its preliminary data $\left(\% \mathrm{~V}_{2}\right.$ peak, rating of perceived exertion) in comparison with traditional moderate-intensity continuous aerobic training (MICT).

Results: Twenty-one sedentary elderly men, aged 60-69 years, performed two exercise protocols: EJ-HIAT, consisting of 3 sets of 2-3-min cycling at $75-85 \% \dot{V}_{2}$ peak with 1-2-min active rests at $50 \% \dot{V O}_{2 \text { peak }}$ between sets, and MICT, consisting of $40-$ min cycling at $65 \% \mathrm{VO}_{2 \text { peak. }}$. The completion rate, defined as the rate of participants who 1) did not demand withdrawal, 2) were not interrupted by the tester, and 3) did not change the workload during either exercise protocol, of EJ-HIAT was similar to that of MICT (EJ-HIAT: 100\%, MICT: 95.2\%). Maximal perceived exertion ratings assessed by Borg scale were also similar between EJ-HIAT and MICT. However, objectively measured maximal intensity assessed by $\% \dot{V O}_{2 \text { peak }}$ was higher for EJ-HIAT than for MICT (EJ-HIAT: $86.0 \pm 5.6 \%$, MICT: $67.1 \pm 6.4 \%$ ).
\end{abstract}

Conclusion: These results suggested that EJ-HIAT has good feasibility and perceived exertion similar to MICT despite having higher objectively measured intensity than MICT. An intervention aimed as identifying the effects of EJ-HIAT on exercise tolerance should be performed in the future.

Trial registration: UMIN000021185 (February 26, 2016).

Keywords: High-intensity interval aerobic training, Elderly men, Feasibility

\section{Background}

Numerous studies have suggested that traditional moderateintensity continuous aerobic training (MICT) improves exercise tolerance and reduces cardiovascular disease risk even in old age [1]. High-intensity interval training (HIIT), which has received substantial attention in several applied scientific fields [2, 3], including sports science [4], obesity prevention [5], cardiac rehabilitation [6, 7], and space medicine [8], is characterized by brief, intermittent bursts of vigorous activity interspersed with active rest periods [9]. Several meta-analyses have suggested that HIIT improves exercise tolerance more effectively than MICT [10-12].

\footnotetext{
* Correspondence: osuka@tmig.or.jp

${ }^{1}$ Research Team for Promoting Independence of the Elderly, Tokyo

Metropolitan Institute of Gerontology, Itabashi, Tokyo, Japan

${ }^{2}$ Space Biomedical Research Group, Astronaut and Operation Control Unit,

Japan Aerospace Exploration Agency, Tsukuba Ibaraki, Japan

Full list of author information is available at the end of the article
}

We previously developed an original HIIT called the Japanese version of high-intensity interval aerobic training (J-HIAT) [13-17], which demonstrated greater improvement of exercise tolerance than MICT despite involving a lower volume and shorter duration of exercise, suggesting that J-HIAT could provide time-efficient training in sedentary people [17]. One consideration when developing the J-HIAT was whether astronauts could participate in exercise training safely, timeefficiently, and feasibly in the international space station $[13,14]$. We believed that this process could be utilized to develop a more time-efficient exercise program to improve exercise tolerance in elderly people, based on the concept that countermeasures for declining exercise tolerance during space flight could be utilized to prevent declining exercise tolerance with aging.

The J-HIAT, consisting of 3 sets of 2-3-min cycling at vigorous intensity (first and second sets: 
$3 \mathrm{~min}$ at $85-90 \% \dot{\mathrm{VO}}_{2 \text { peak, }}$ third set: $3 \mathrm{~min}$ at 80 $\left.-85 \% \dot{\mathrm{VO}}_{2 \text { peak }}\right)$ with 2 -min active rests at $50 \% \dot{\mathrm{VO}}_{2 \text { peak }}$ between each set, was developed for healthy, sedentary younger adults [17]. However, cross-sectional and longitudinal data have indicated that maximal oxygen consumption declines by approximately $10 \%$ per decade in healthy men $[18,19]$. The J-HIAT was developed for younger adults and thus may be too difficult for elderly populations even if the workload is determined relatively. In this study, therefore, we aimed to identify 1) the feasibility of a novel elderly Japanese male version of the HIAT (EJ-HIAT) and 2) preliminary data (heart rate [HR], percentage of maximal oxygen consumption $\left[\% \dot{\mathrm{V}} \mathrm{O}_{2 \text { peak }}\right]$, and rating of perceived exertion [RPE]) for comparison with traditional MICT.

\section{Methods}

\section{Study procedures and participants}

We conducted this study in accordance with the guidelines of the Declaration of Helsinki. The study protocol was approved by the Ethics Committee of the University of Tsukuba, Tsukuba University Hospital, and the Japan Aerospace Exploration Agency. This feasibility study was registered with the University Medical Information Network (UMIN000021185) in February 2016. Twentythree elderly men, aged 60-69 years, were recruited from the southern area of Ibaraki through newspaper advertisements in March 2016 describing the inclusion criteria for the study: 1) no smoking history within 1 year, 2) not restricted by their doctor from participating in exercise, 3) not regularly participating in aerobic exercise at moderate intensity (assessed using the Borg RPE scale; <13, "somewhat hard"), 4) no participation in another clinical trial within 1 year, and 5) agreement to participate. All applications were received by telephone. After the study was explained, all participants provided written informed consent. Based on the results of a screening test (described below), participants were excluded by doctor who 1) had severe heart disease, cerebrovascular disease, or kidney disease, 2) were diagnosed electrocardiographically by a medical doctor with severe arrhythmia during rest and cardiopulmonary exercise (CPX), or 3) had knee joint pain during CPX.

\section{Screening test}

After medical history taking, blood tests, electrocardiography, and CPX were performed to evaluate patients' safety to perform exercise training. A nurse collected fasting blood samples from the antecubital vein of each participant. Total cholesterol, high-density lipoprotein cholesterol, low-density lipoprotein cholesterol, triglyceride, free fatty acid, urea nitrogen, creatinine, serum iron, white blood cell count, red blood cell count, hemoglobinometry, hematocrit, fasting blood glucose, $\mathrm{Hb}-\mathrm{A} 1 \mathrm{c}$, immunoreactive insulin, homeostatic model assessment insulin resistance, and $\mathrm{N}$-terminal pro-brain natriuretic peptide were measured and analyzed by Kotobiken Medical Laboratories (Ibaraki, Japan). Electrocardiography (ECG-1500, Nihon Kohden, Tokyo, Japan and DS-2150, Fukuda Denshi, Tokyo, Japan) was performed by a medical doctor to determine whether participants had severe arrhythmias during rest and CPX. CPX was performed to determine $\dot{\mathrm{V}} \mathrm{O}_{2 \text { peak. Details of the CPX measurement }}$ have been previously described [20]. Briefly, participants pedaled on a cycling ergometer (75XL III; Konami Sports Life, Tokyo, Japan) until physical exhaustion. After warming up for $2 \mathrm{~min}$ at $20 \mathrm{~W}$, the workload increased after $1 \mathrm{~min}$ by $0.25 \mathrm{kp}$ with $60 \mathrm{rpm}$ of rotations. $\mathrm{VO}_{2}$ was measured using the breath-by-breath method with a computerized indirect calorimeter (Fitmate Pro, Cosmed, Rome, Italy) that can measure each 30-s average $\dot{\mathrm{VO}}_{2}$. We used the value at the final 30-s interval as an indicator of $\dot{\mathrm{VO}}_{2 \text { peak }}$.

\section{Exercise protocols}

To determine the appropriate intensity of MICT and EJ-HIAT for each participant, we calculated a simple linear regression equation using the values of $\mathrm{VO}_{2}(\mathrm{Y})$ and workload $(\mathrm{X})$ per 30 s. First, $\% \dot{\mathrm{V}} \mathrm{O}_{2 \text { peak }}$ values were applied to the equation, and we calculated the intensity of both protocols for each participant [17]. In the first week, participants performed MICT; which consisted of 40-min cycling at $60 \% \dot{\mathrm{VO}}_{2 \text { peak }}$ (Fig. 1a). This traditional exercise protocol has been recommended as a standard protocol for maintaining cardiovascular health in elderly people by the American College of Sports Medicine and American Heart Association [1]. The next week, participants performed the EJ-HIAT, consisting of 3 sets of $2-3-\mathrm{min}$ cycling at vigorous intensity (first set: $3 \mathrm{~min}$ at $85 \% \mathrm{VO}_{2 \text { peak }}$, second set: $2 \mathrm{~min}$ at $80 \% \dot{\mathrm{VO}}_{2 \text { peak }}$, third set: $2 \mathrm{~min}$ at $\left.75 \% \dot{\mathrm{VO}}_{2 \text { peak }}\right)$ with $1-2$ min active rests at $50 \% \dot{\mathrm{VO}}_{2 \text { peak }}$ (first rest: $2 \mathrm{~min}$, second rest: 1 min) between each set (Fig. 1b). The EJ-HIAT was amended specifically to be suited to elderly people. The EJ-HIAT has declining intensities at vigorous intensity $\left(-5 \% \dot{\mathrm{VO}}{ }_{2 \text { peak }}\right.$ at second set, $-10 \% \dot{\mathrm{V} O}{ }_{2 \text { peak }}$ at third set $)$, and decreased durations of vigorous intensity and active rest $(-1$ min during the second and third set of vigorous intensity and second set of active rest). These slight adjustments were performed depending on our heuristics. Consequently, the EJ-HIAT total duration was reduced by $3 \mathrm{~min}$ compared with the J-HIAT. The EJ-HIAT could be finished in 15 min: a 2-min warm-up, 10-min exercise, and 3-min cool-down. We decreased the actual workload by $10 \%$ from the calculated workloads for both protocols, since we anticipated that the participants would have difficulty performing these protocols without practice. 

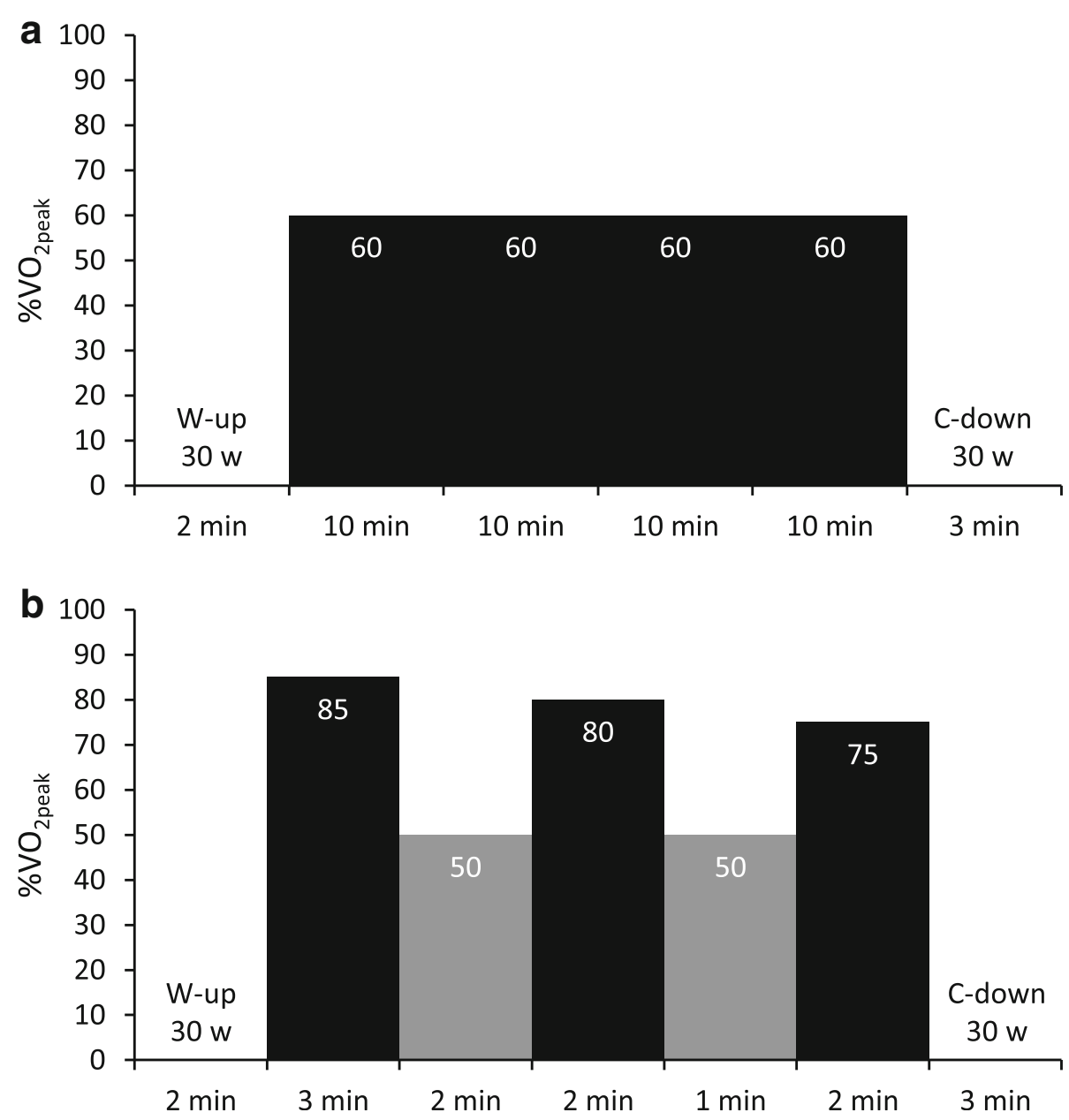

Fig. 1 a EJ-HIAT and b MICT exercise protocols

\section{Primary outcome measure}

The primary outcome measure was the feasibility of each exercise protocol, assessed by completion rate. Completion was defined as participants 1) not demanding to withdraw, 2) not interrupted by the tester, and 3) who did not change the workload during either exercise protocol.

\section{Secondary outcome measures}

Percent $\dot{\mathrm{VO}}_{2 \text { peak }}, \% \mathrm{HR}_{\text {peak }}$, and $\mathrm{RPE}$ during the both exercise protocols were measured to assess their intensity. All data were collected from warm-up to cool-down. $\dot{\mathrm{VO}}_{2}$ was measured every $30 \mathrm{~s}$ using the breath-by-breath method with a Fitmate Pro. HR and RPE data were collected at the last $15 \mathrm{~s}$ of each minute. HR was observed using electrocardiography (DS-2150, Fukuda Denshi, Tokyo, Japan). Overall body, breathing, and leg RPE were assessed using Borg's RPE scale, ranging from 6-20 (6: no exertion, 11: light, 13: somewhat hard, 15: hard, 17: very hard, 20: maximal exertion).

\section{Statistical analysis}

McNemar's test and paired t tests were applied to compare differences in completion rate, average and peak point of $\dot{\mathrm{VO}}_{2}, \mathrm{HR}$, and RPE between the two exercise protocols. All analyses were performed using SPSS software (version 24.0, IBM Corp., Armonk, NY). $P$ values of $<0.05$ were considered significant. All data are reported as $\mathrm{n}(\%)$ or mean \pm standard deviation.

\section{Results}

\section{Study attrition}

Before screening, one participant dropped out because of time constraints. After screening, one participant was excluded because of left anterior fascicular block arrhythmia. The other 21 participants performed both exercise protocols.

\section{Participant characteristics}

Table 1 summarizes the characteristics of the study participants at screening. The participants' average age was $67.6 \pm 1.8$ years. Twelve participants $(57.1 \%)$ had mild diseases controlled by medication. 
Table 1 Characteristics of study participants at the screening test $(n=21)$

\begin{tabular}{|c|c|}
\hline Age, years & $67.6 \pm 1.8$ \\
\hline Height, cm & $167.1 \pm 6.6$ \\
\hline Weight, kg & $68.1 \pm 8.7$ \\
\hline Systolic blood pressure, $\mathrm{mmHg}$ & $134.8 \pm 15.4$ \\
\hline Diastolic blood pressure, $\mathrm{mmHg}$ & $84.0 \pm 8.9$ \\
\hline Resting heart rate, beats/min & $70.3 \pm 7.5$ \\
\hline Hypertension, $n(\%)$ & $7(33.3)$ \\
\hline Diabetes, $n(\%)$ & $4(19.0)$ \\
\hline Hyperlipidemia, $n$ (\%) & $2(9.5)$ \\
\hline Arthralgia, $n(\%)$ & $10(47.6)$ \\
\hline Arrhythmia, $n(\%)$ & $6(28.6)$ \\
\hline$\dot{\mathrm{V}}_{2 \text { peak }} \mathrm{mL} / \mathrm{kg} / \mathrm{min}$ & $27.8 \pm 4.2$ \\
\hline Heart rate peak, beats/min & $154.9 \pm 14.9$ \\
\hline Albumin, g/dL & $4.3 \pm 0.2$ \\
\hline Total cholesterol, mg/dL & $210.0 \pm 26.3$ \\
\hline High-density lipoprotein cholesterol, mg/dL & $63.6 \pm 14.5$ \\
\hline Low-density lipoprotein cholesterol, mg/dL & $124.7 \pm 20.6$ \\
\hline Triglyceride, mg/dL & $105.3 \pm 41.6$ \\
\hline Free fatty acid, mEq/L & $0.7 \pm 0.2$ \\
\hline Urea nitrogen, mg/dL & $15.8 \pm 2.6$ \\
\hline Creatinine, mg/dL & $0.9 \pm 0.1$ \\
\hline Serum iron, $\mu \mathrm{g}$ & $111.5 \pm 43.0$ \\
\hline White blood cell, $\mu \mathrm{L}$ & $6166.7 \pm 2050.4$ \\
\hline Red blood cell, $10^{4} \mu \mathrm{L}$ & $507.2 \pm 48.3$ \\
\hline Hemoglobinometry & $15.5 \pm 0.9$ \\
\hline Hematocrit, \% & $47.8 \pm 2.8$ \\
\hline Fasting blood glucose, $\mathrm{mg} / \mathrm{dL}$ & $106.6 \pm 18.3$ \\
\hline $\mathrm{Hb}-\mathrm{A} 1 \mathrm{c}, \%$ & $6.1 \pm 0.7$ \\
\hline Immunoreactive insulin, $\mu \mathrm{U} / \mathrm{mL}$ & $6.4 \pm 2.9$ \\
\hline HOMA-R & $1.7 \pm 1.0$ \\
\hline High-sensitivity C-reactive protein (>0.2 mg/dL), $n(\%)$ & $2(9.5)$ \\
\hline NT-proBNP (>400 pg/mL), n (\%) & $0(0)$ \\
\hline
\end{tabular}

HOMA-R homeostatic model assessment of insulin resistance, NT-proBNP $\mathrm{N}$-terminal pro-brain natriuretic peptide)

\section{Adverse events and safety}

No severe adverse events were observed during either exercise protocol, but transient asymptomatic tachycardia was observed in one participant during the EJ-HIAT cool-down. We quickly changed the workload to no-load and checked whole body symptoms whether hypotension and/or an anginal attack were initiated. Tachycardia was improved within $1 \mathrm{~min}$, thereafter, did not relapse. This episode was appropriately assessed and treated by the medical doctor.

\section{Completion rate}

One participant did not complete the MICT; he demanded a reduction in workload (completion rate, 95.2\%). All participants completed the EJ-HIAT. Although the EJHIAT completion rate was higher, the protocols could not be compared statistically since the EJ-HIAT completion rate was $100 \%$.

\section{Patterns of HR change}

The changes to HR are shown in Fig. 2. In the MICT, HR increased gradually over $40 \mathrm{~min}$ and peaked at 42:00 (HR: $123.8 \pm 16.2 \mathrm{bpm}, \% \mathrm{HR}_{\text {peak }}: 80.1 \pm 8.4 \%$ ). In the EJHIAT, HR increased or decreased depending the workload, with the highest observed at 5:00 (HR: $139.1 \pm 15.7$ bpm, \%HR peak: $89.8 \pm 5.0 \%$ ), 9:00 (HR: $\left.136.3 \pm 16.5 \mathrm{bpm}, \% \mathrm{HR}_{\text {peak }}: 84.1 \pm 6.6 \%\right)$, and $12: 00$ (HR: $138.6 \pm 17.3 \mathrm{bpm}, \% \mathrm{HR}_{\text {peak }}: 89.5 \pm 6.9 \%$ ). There were significant differences in HR between the protocols at each minute from 3:00-13:00 and in the peak point of HR at 42:00 in the MICT and at 5:00 in the EJ-HIAT.

\section{Oxygen uptake kinetics}

$\dot{\mathrm{V}} \mathrm{O}_{2}$ kinetics are shown in Fig. 3. In the MICT, $\dot{\mathrm{VO}}_{2}$ values increased gradually for the first $15 \mathrm{~min}$, and then stabilized at approximately $17-18 \mathrm{ml} / \mathrm{kg} / \mathrm{min}\left(63-65 \% \mathrm{~V}_{2}\right.$ peak $)$. The highest $\dot{\mathrm{V}} \mathrm{O}_{2}$ value occurred at 14:30 $\left(\dot{\mathrm{V}}_{2}: 18.6 \pm 2.8 \mathrm{ml} /\right.$ $\left.\mathrm{kg} / \mathrm{min}, \% \dot{\mathrm{VO}}_{2 \text { peak }}: 67.1 \pm 6.4 \%\right)$. In the EJ-HIAT, $\dot{\mathrm{VO}}{ }_{2}$ values increased or decreased depending on workload, with the highest observed at 5:00 $\left(\dot{\mathrm{VO}}_{2}: 25.1 \pm 3.2 \mathrm{ml} / \mathrm{kg} / \mathrm{min}\right.$, $\left.\% \dot{\mathrm{V}}{ }_{2 \text { peak }}: 90.7 \pm 5.8 \%\right), 9: 00\left(\dot{\mathrm{VO}}_{2}: 24.3 \pm 3.4 \mathrm{ml} / \mathrm{kg} / \mathrm{min}\right.$, $\left.\% \dot{\mathrm{VO}}{ }_{2 \text { peak }}: 87.6 \pm 6.7 \%\right)$, and 12:00 $\left(\dot{\mathrm{VO}}_{2}: 23.8 \pm 3.1 \mathrm{ml} / \mathrm{kg} /\right.$ min, \% $\left.\dot{\mathrm{VO}}_{2 \text { peak }}: 86.0 \pm 5.6 \%\right) . \dot{\mathrm{VO}_{2}}$ significantly differed between the exercise protocols at 30-s intervals at $0: 30$, 2:30-6:30, 7:30-12:30, and 13:30-15:00. Peak $\dot{\mathrm{VO}}_{2}$ value also significantly differed at 14:30 in the EJ-HIAT and at 5:00 in the MICT.

\section{Patterns of RPE change}

The change of RPE is shown in Fig. 4a, b, and c. In the MICT, whole-body, breathing, and leg RPE values increased gradually over $40 \mathrm{~min}$, with the highest observed at 42:00 (whole body: $13.0 \pm$ 2.0, breathing: $12.9 \pm 1.8$, legs: $13.7 \pm 1.8)$. In the EJ-HIAT, the highest whole-body RPE values were observed at 5:00 (12.4 \pm 1.5$)$, 9:00 (12.5 \pm 1.4$)$, and 12:00 (12.6 \pm 1.5$)$. Whole-body RPE values at each minute significantly differed between the exercise protocols at 4:00-5:00, 8:00-9:00, 11:00-12:00, and 15:00. The highest breathing RPE values in the EJ-HIAT were observed at 5:00 (12.7 \pm 1.5$)$, 9:00 (12.7 \pm 1.5$)$, and 11:00 (12.5 \pm 1.4$)$. Breathing RPE values at each minute significantly differed between the exercise protocols at 4:00-5:00, 8:00-9:00, 11:00, and 14:00-15:00. The highest RPE values regarding legs in the EJ-HIAT were observed at 5:00 (13.0 \pm 1.5$)$, 9:00 (13.3 \pm 1.6$)$, and 12:00 (13.0 \pm 1.6$)$. Leg RPE values at each minute significantly differed between the exercise protocols at 4:00-5:00, 8:00-9:00, 11:00-12:00, and 15:00. There were 


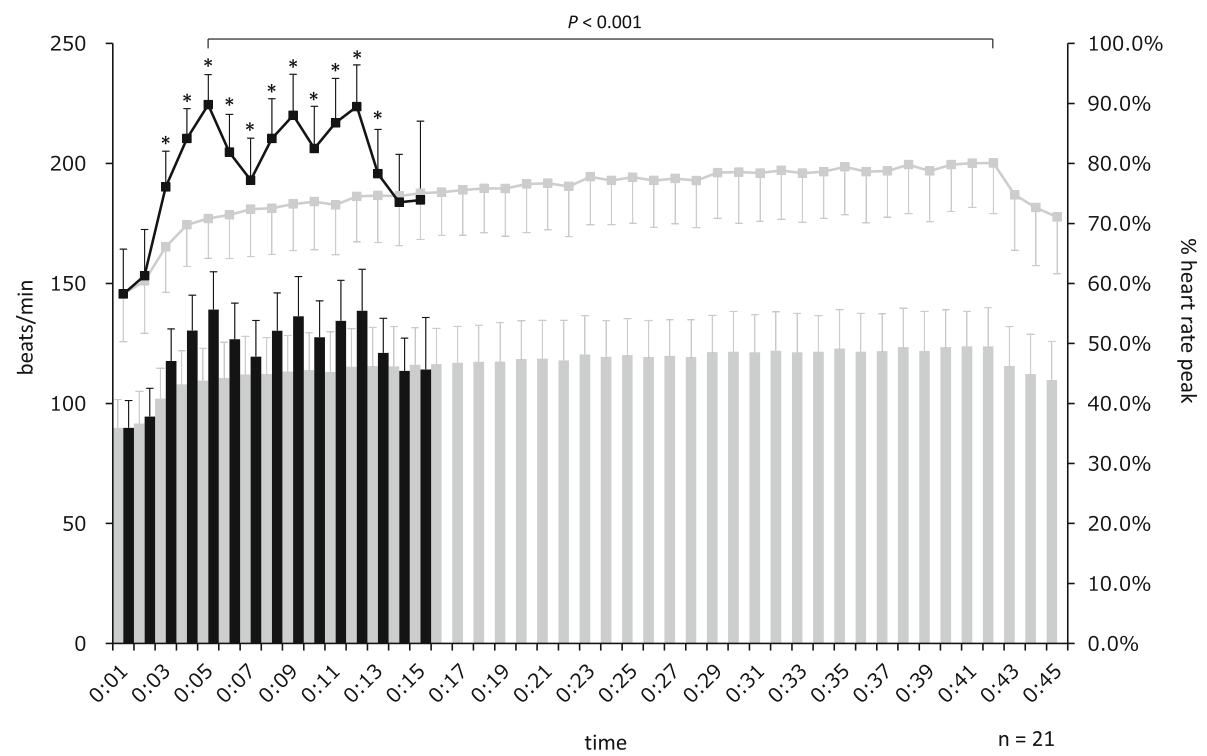

Fig. 2 Comparison of HR between the EJ-HIAT and MICT protocols. Note: Line graph indicates the means and standard deviations of \%HR peak. The bar graph indicates the means and standard deviations of HR. *: $P<0.05$ (comparison with MICT)

no significant differences in peak RPE values between the exercise protocols.

\section{Discussion}

This study is the first to report the feasibility of a novel HIIT protocol for elderly men (the EJ-HIAT) and provide preliminary data regarding $\mathrm{HR}, \dot{\mathrm{V}} \mathrm{O}_{2}$, and RPE in comparison with traditional MICT. The EJ-HIAT had a similar completion rate and maximal perceived exertion to MICT, but greater objectively measured exercise intensity $\left(\dot{\mathrm{VO}}_{2}\right.$ and $\left.\mathrm{HR}\right)$. These results suggest that the EJ-HIAT protocol has good feasibility and suitable intensity, warranting a future clinical intervention aimed to demonstrate its effects on exercise tolerance and the cardiovascular system.

\section{Feasibility of EJ-HIAT}

Some previous studies, especially in European countries, have evaluated HIIT in elderly people. Wisloff et al. reported superior effects of walking-type HIIT on

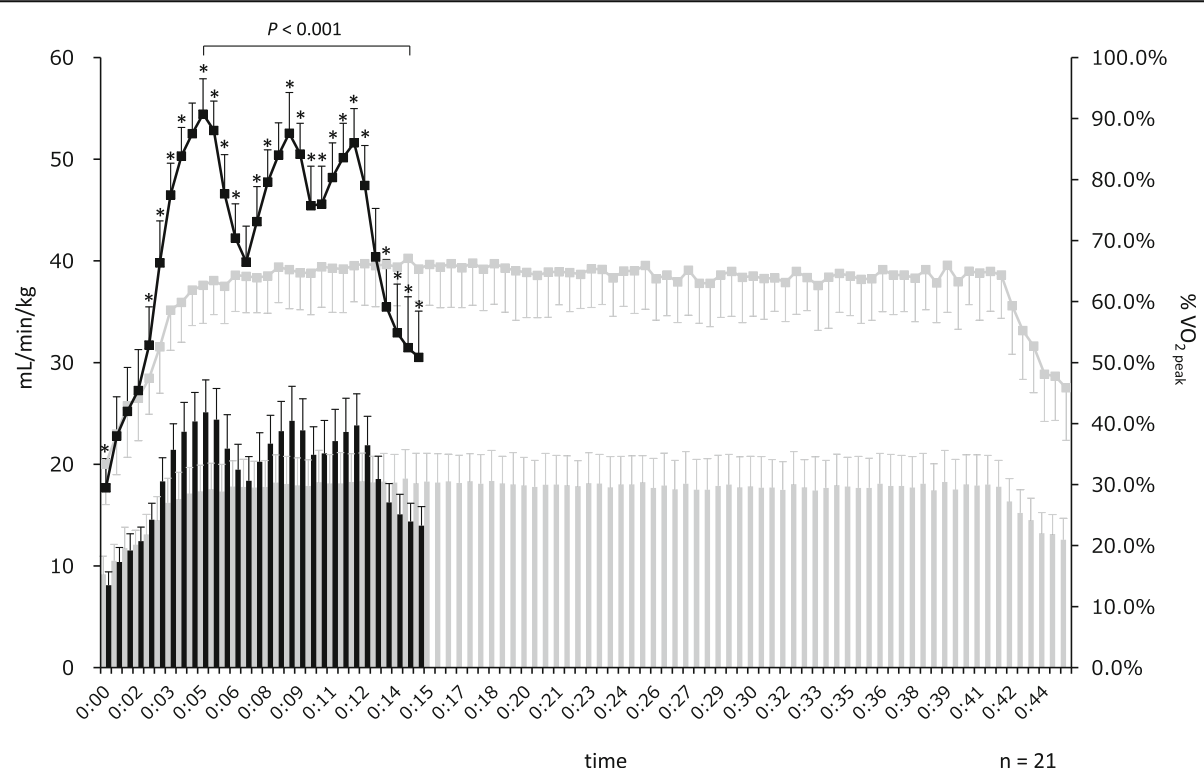

Fig. 3 Comparison of $\dot{V} O 2$ between the EJ-HIAT and MICT protocols. Note: Line graph indicates the means and standard deviations of \%VंO 2 peak. The bar graph indicates the means and standard deviations of $\dot{\mathrm{VO}}_{2}$. $:$ : $P<0.05$ (comparison with MICT) 

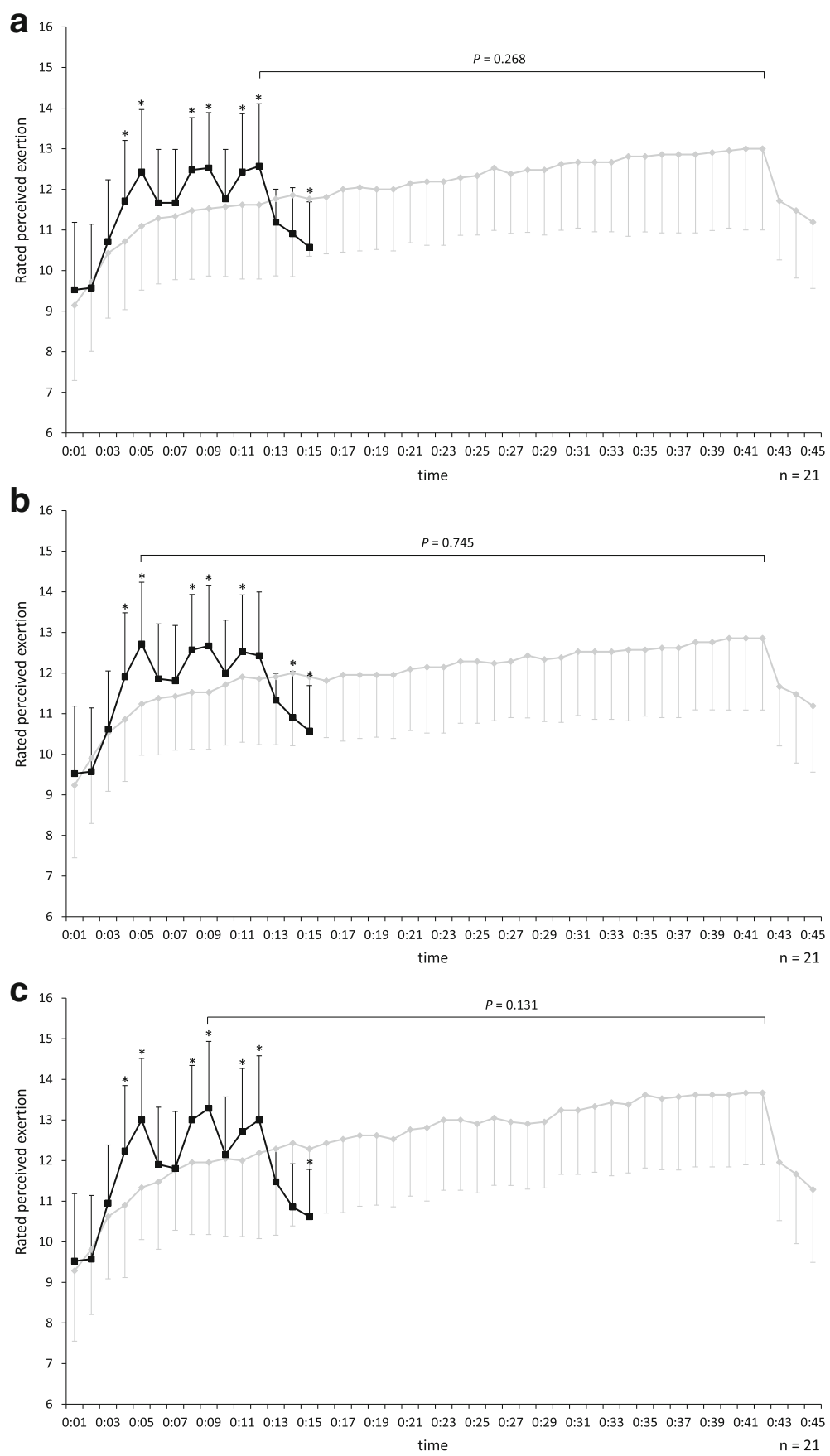

Fig. 4 a :whole body, b: breathing, and c: legs. Comparison of RPE between the EJ-HIAT and MICT protocols. Note: Line graph indicates the means and standard deviations of RPE. *: $P<0.05$ (comparison with MICT)

cardiovascular function-related outcomes compared to MICT and demonstrated that the HIIT was feasible even in elderly participants with chronic heart failure and impaired cardiovascular function; the participation rate of HIIT and MICT were $92 \pm 2 \%$ and $95 \pm 3 \%$, respectively [6]. Iellamo et al. provided walking-type HIIT to patients with heart failure and observed $100 \%$ compliance to HIIT [21]. Haykowsky et al. reviewed 7 studies of HIIT in patients with heart failure and reduced ejection fraction and found similar completion rates between HIIT and MICT protocols (HIIT: 90\%, MICT: 91\%) [22]. These reports suggest that well-designed HIIT protocols have similar feasibility to MICT even in heart failure patients. Despite their good completion rates, these HIIT protocols have comparable durations to MICT (30-40 min). By contrast, the EJ-HIAT can be finished in $15 \mathrm{~min}$, making it 
more feasible with regard to exercise duration. An intervention to assess the cardiovascular effects of EJ-HIAT is necessary in the future.

\section{Preliminary data}

Our preliminary data indicate that the objective intensity of the EJ-HIAT as assessed by $\dot{\mathrm{VO}}_{2}$ was temporarily but significantly higher than that of the MICT. Although we targeted vigorous intensity to $70-75 \% \mathrm{~V}_{2 \text { peak }}$, the actual data indicated that $86-90 \% \mathrm{~V}_{2 \text { peak }}$ was attained. Thus, actual intensity was approximately $15 \%$ higher than estimated. We may have underestimated $\dot{\mathrm{VO}}_{2 \text { peak }}$ at the screening, since participants were not used to the cycling test. Therefore, we will need to re-measure $\dot{\mathrm{V}}_{2 \text { peak }}$ and adjust intensities accordingly during the intervention period in the future. Although objective intensity measurements $\left(\mathrm{HR}\right.$ and $\dot{\mathrm{V}} \mathrm{O}_{2}$ ) were significantly higher, peak RPE values were not significantly different between the EJHIAT and MICT. RPE reflects not only physical exertion but also psychological exertion. Some participants gave opinions such as "MICT was boring," indication that its duration was too long. These discomforts may negatively influence RPE. Bartlett et al. reported that ratings of perceived enjoyment were greater after undertaking HIIT compared with MICT, even if the RPE was higher for the HIIT than for MICT [23]. These results suggest that HIIT may be more enjoyable than MICT. Therefore, the HIIT may be advantageous with regard to participants' enjoyment of vigorous activity, since the protocol is characterized by fluctuating intensity.

\section{Physiological and metabolic adaptations}

Although the mechanisms regarding differences in physiological and metabolic adaptations between MICT and HIIT have yet to be definitively examined [9], exercise intensity may be a factor in the time-cost superiority of HIIT for those adaptations. Peroxisome proliferatoractivated receptor $\gamma$ coactivator (PGC)- $1 \alpha$ is regarded as a key regulator of mitochondrial biogenesis in skeletal muscle [24], and exercise intensity was reported to influence its activation [25]. Burgomaster et al. reported that both MICT and HIIT increased peak oxygen uptake and total protein content of PGC- $1 \alpha$ measured in muscle biopsy samples obtained before and after 6 weeks of training; nevertheless, total exercise volume was $90 \%$ lower in the HIIT [26]. In this way, physiological and metabolic adaptations during exercises after both training protocols would occur via the same pathway, but the time-cost influence of HIIT on those adaptations would be superior to those of MICT.

\section{Practical applications}

Lack of time is one of the most common reasons that inhibits participation in exercise [27]. By contrast, the
EJ-HIAT can be completed in only $15 \mathrm{~min}$. Therefore, if the efficacy of the EJ-HIAT on cardiovascular system is validated by future trials, this protocol will provide a useful exercise program for older people who want to exercise efficiently.

\section{Limitations}

This study has two limitations. First, it has a possibility of selection bias, since only elderly men participated in this study. Therefore, it is uncertain whether EJ-HIAT has suitable intensity in elderly women. Second, a blinded assessment was not conducted, so there is a possibility of observation bias in this study.

\section{Conclusion}

Our preliminary data suggest that EJ-HIAT has feasibility comparable to MICT despite its significantly higher objectively measured intensity. An intervention aimed at identifying the effects of EJ-HIAT on exercise tolerance is needed in the future.

\section{Abbreviations}

CPX: Cardiopulmonary exercise test; EJ-HIAT: Elderly Japanese male version of high-intensity interval aerobic training; HIIT: High-intensity interval training; HR: Heart rate; MICT: Moderate-intensity continuous aerobic training; RPE: Rating of perceived exertion

\section{Acknowledgements}

The authors acknowledge the excellent work and dedication of the staff at the Japan Aerospace Exploration Agency and Dr. Tomoaki Matsuo (National Institute of Occupational Safety and Health).

Funding

This study was supported by JSPS KAKENHI Grant Number 15 J11056.

Availability of data and materials

All data generated or analysed during this study are included in this published article.

\section{Authors' contributions}

YO was involved in study design, data collection, and data analysis. KT was involved in study design and data collection. $\mathrm{MM}$ and $\mathrm{AH}$ were involved in data collection. All authors were involved in the conception of the study, data interpretation, and review and approval of the manuscript.

Ethics approval and consent to participate

The study was approved by the Ethics Committee of the University of Tsukuba (Tai27-74), Tsukuba University Hospital (H27-236), and the Japan Aerospace Exploration Agency (YuHiYu1225001).

\section{Consent for publication}

Not applicable.

\section{Competing interests}

The authors declare that they have no competing interests.

\section{Publisher's Note}

Springer Nature remains neutral with regard to jurisdictional claims in published maps and institutional affiliations.

Author details

${ }^{1}$ Research Team for Promoting Independence of the Elderly, Tokyo Metropolitan Institute of Gerontology, Itabashi, Tokyo, Japan. ${ }^{2}$ Space Biomedical Research Group, Astronaut and Operation Control Unit, Japan 
Aerospace Exploration Agency, Tsukuba Ibaraki, Japan. ${ }^{3}$ Faculty of Medicine, Department of Cardiovascular Surgery, University of Tsukuba, Tsukuba, Ibaraki, Japan. ${ }^{4}$ Graduate School of Comprehensive Human Sciences, University of Tsukuba, Tsukuba, Ibaraki, Japan. ${ }^{5}$ Faculty of Health and Sport Sciences, University of Tsukuba, Tsukuba, Ibaraki, Japan.

Received: 17 April 2017 Accepted: 9 August 2017

Published online: 24 August 2017

\section{References}

1. Nelson ME, Rejeski WJ, Blair SN, Duncan PW, Judge JO, King AC, Macera CA, Castaneda-Sceppa C. Physical activity and public health in older adults: recommendation from the American College of Sports Medicine and the American Heart Association. Circulation. 2007;116(9):1094-105.

2. Wisloff $U$, Ellingsen $\mathrm{O}, \mathrm{Kemi} \mathrm{OJ}$. High-intensity interval training to maximize cardiac benefits of exercise training? Exerc Sport Sci Rev. 2009;37(3):139-46.

3. Biddle SJ, Batterham AM. High-intensity interval exercise training for public health: a big HIT or shall we HIT it on the head? Int J Behav Nutr Phys Act. 2015;12(1):95.

4. Tabata I, Nishimura K, Kouzaki M, Hirai Y, Ogita F, Miyachi M, Yamamoto K. Effects of moderate-intensity endurance and high-intensity intermittent training on anaerobic capacity and VO2max. Med Sci Sports Exerc. 1996; 28(10):1327-30.

5. Tjonna AE, Lee SJ, Rognmo O, Stolen TO, Bye A, Haram PM, Loennechen JP, Al-Share QY, Skogvoll E, Slordahl SA, et al. Aerobic interval training versus continuous moderate exercise as a treatment for the metabolic syndrome: a pilot study. Circulation. 2008;118(4):346-54.

6. Wisloff U, Stoylen A, Loennechen JP, Bruvold M, Rognmo O, Haram PM, Tjonna AE, Helgerud J, Slordahl SA, Lee SJ, et al. Superior cardiovascular effect of aerobic interval training versus moderate continuous training in heart failure patients: a randomized study. Circulation. 2007;115(24):3086-94.

7. Meyer P, Gayda M, Juneau M, Nigam A. High-intensity aerobic interval exercise in chronic heart failure. Curr Heart Fail Rep. 2013;10(2):130-8.

8. Ploutz-Snyder LL, Downs M, Ryder J, Hackney K, Scott J, Buxton R, Goetchius $\mathrm{E}$, Crowell B. Integrated resistance and aerobic exercise protects fitness during bed rest. Med Sci Sports Exerc. 2014;46(2):358-68.

9. Gibala MJ, Little JP, Macdonald MJ, Hawley JA. Physiological adaptations to low-volume, high-intensity interval training in health and disease. J Physiol. 2012:590(Pt 5):1077-84

10. Haykowsky MJ, Timmons MP, Kruger C, McNeely M, Taylor DA, Clark AM. Meta-analysis of aerobic interval training on exercise capacity and systolic function in patients with heart failure and reduced ejection fractions. Am J Cardiol. 2013;111(10):1466-9.

11. Pattyn N, Coeckelberghs E, Buys R, Cornelissen VA, Vanhees L. Aerobic interval training vs. moderate continuous training in coronary artery disease patients: a systematic review and meta-analysis. Sports Med. 2014:44(5):687-700.

12. Ramos JS, Dalleck LC, Tjonna AE, Beetham KS, Coombes JS. The impact of high-intensity interval training versus moderate-intensity continuous training on vascular function: a systematic review and meta-analysis. Sports Med. 2015;45(5):679-92.

13. Matsuo T, Ohkawara K, Seino S, Shimojo N, Yamada S, Ohshima H, Tanaka K, Mukai $C$. An exercise protocol designed to control energy expenditure for long-term space missions. Aviat Space Environ Med. 2012;83(8):783-9.

14. Matsuo T, Seino S, Ohkawara K, Tanaka K, Yamada S, Ohshima H, Mukai C. A preliminary exercise study of Japanese Version of High-intensity Interval Aerobic Training (J-HIAT). Trans Jpn Soc Aeronaut Space Sci, Aerospace Technol Jpn. 2012;10(28):Tp_15-7.

15. Matsuo T, Ohkawara K, Seino S, Shimojo N, Yamada S, Ohshima H, Tanaka K, Mukai $\mathrm{C}$. Cardiorespiratory fitness level correlates inversely with excess postexercise oxygen consumption after aerobic-type interval training. BMC Res Notes. 2012:5:646.

16. Matsuo T, Saotome K, Seino S, Eto M, Shimojo N, Matsushita A, lemitsu M, Ohshima H, Tanaka K, Mukai C. Low-volume, high-intensity, aerobic interval exercise for sedentary adults: $\mathrm{VO}(2) \mathrm{max}$, cardiac mass, and heart rate recovery. Eur J Appl Physiol. 2014;114(9):1963-72.

17. Matsuo T, Saotome K, Seino S, Shimojo N, Matsushita A, lemitsu M, Ohshima H, Tanaka K, Mukai C. Effects of a low-volume aerobic-type interval exercise on VO2max and cardiac mass. Med Sci Sports Exerc. 2014;46(1):42-50.

18. Ogawa T, Spina RJ, Martin WH 3rd, Kohrt WM, Schechtman KB, Holloszy JO, Ehsani AA. Effects of aging, sex, and physical training on cardiovascular responses to exercise. Circulation. 1992;86(2):494-503.
19. Rogers MA, Hagberg JM, Martin WH 3rd, Ehsani AA, Holloszy JO. Decline in VO2max with aging in master athletes and sedentary men. J Appl Physiol (1985). 1990;68(5):2195-9.

20. Tanaka K, Takeshima N, Kato T, Niihata S, Ueda K. Critical determinants of endurance performance in middle-aged and elderly endurance runners with heterogeneous training habits. Eur J Appl Physiol Occup Physiol. 1990; 59(6):443-9.

21. lellamo F, Manzi V, Caminiti G, Vitale C, Castagna C, Massaro M, Franchini A, Rosano G, Volterrani M. Matched dose interval and continuous exercise training induce similar cardiorespiratory and metabolic adaptations in patients with heart failure. Int J Cardiol. 2013;167(6):2561-5.

22. Haykowsky MJ, Liang Y, Pechter D, Jones LW, McAlister FA, Clark AM. A meta-analysis of the effect of exercise training on left ventricular remodeling in heart failure patients: the benefit depends on the type of training performed. J Am Coll Cardiol. 2007;49(24):2329-36.

23. Bartlett JD, Close GL, MacLaren DP, Gregson W, Drust B, Morton JP. Highintensity interval running is perceived to be more enjoyable than moderate-intensity continuous exercise: implications for exercise adherence. J Sports Sci. 2011;29(6):547-53.

24. Wu Z, Puigserver P, Andersson U, Zhang C, Adelmant G, Mootha V, Troy A, Cinti S, Lowell B, Scarpulla RC, et al. Mechanisms controlling mitochondrial biogenesis and respiration through the thermogenic coactivator PGC-1. Cell. 1999;98(1):115-24

25. Egan B, Carson BP, Garcia-Roves PM, Chibalin AV, Sarsfield FM, Barron N, McCaffrey N, Moyna NM, Zierath JR, O'Gorman DJ. Exercise intensitydependent regulation of peroxisome proliferator-activated receptor coactivator-1 mRNA abundance is associated with differential activation of upstream signalling kinases in human skeletal muscle. J Physiol. 2010;588(Pt 10):1779-90.

26. Burgomaster KA, Howarth KR, Phillips SM, Rakobowchuk M, Macdonald MJ, McGee SL, Gibala MJ. Similar metabolic adaptations during exercise after low volume sprint interval and traditional endurance training in humans. J Physiol. 2008:586(1):151-60.

27. Trost SG, Owen N, Bauman AE, Sallis JF, Brown W. Correlates of adults participation in physical activity: review and update. Med Sci Sports Exerc. 2002;34(12):1996-2001

\section{Submit your next manuscript to BioMed Central and we will help you at every step:}

- We accept pre-submission inquiries

- Our selector tool helps you to find the most relevant journal

- We provide round the clock customer support

- Convenient online submission

- Thorough peer review

- Inclusion in PubMed and all major indexing services

- Maximum visibility for your research

Submit your manuscript at www.biomedcentral.com/submit
) Biomed Central 